\title{
Prediction of slope instabilities due to deep-seated gravitational creep
}

\author{
E. Brückl ${ }^{1}$ and M. Parotidis ${ }^{2, *}$ \\ ${ }^{1}$ Geophysics Department, Vienna University of Technology, Austria \\ ${ }^{2}$ Geophysics Department, Freie Universitaet Berlin, Germany \\ *now at: Geomechanics International Inc., Mainz, Germany
}

Received: 20 October 2004 - Revised: 10 January 2005 - Accepted: 17 January 2005 - Published: 31 January 2005

Part of Special Issue "Landslides and debris flows: analysis, monitoring, modeling and hazard"

\begin{abstract}
Deep-seated gravitational creep in rock slopes, rock-flow or sackung is a special category of massmovement, in which long-lasting small-scale movements prevail. The prime causes of these mass movements in the Alpine area seem to have been glacial retreat at $\sim 15000$ a B.P. Many sackung stabilize and some undergo the transition to rapid sliding. This paper concentrates on four massmovements in crystalline complexes of the Austrian Alps which have been investigated for aspects of deep-seated gravitational creep and prediction of the transition to rapid sliding. The present-day extent of the creeping or sliding of the rock mass has been modelled by a process of progressive, stress induced damage. Subcritical crack growth has been assumed to control this process and also the velocity of the mass movement. A sliding surface and decreasing Coulomb stress at this surface as a function of slip is a precondition for instability. The development of the four examples has been modelled successfully by a rotational slider block model and the conception of subcritical crack growth and progressive smoothing of the sliding surface. The interrelations between velocity, pore water pressure, seismic activity and the state of the sliding surface have been derived. Finally we discuss how the hypothesis inherent in the models presented could be validated and used for prediction.
\end{abstract}

\section{Introduction}

Deep-seated gravitational creep in rock slopes is a special category of mass-movement, in which long-lasting smallscale movements prevail (e.g. Nemcok et al., 1972); the terms sackung (sagging) and rock-flow have also been used (Zischinsky, 1969; Hutchinson, 1988; Dikau et al., 1996). Typically, slopes involved in deep-seated gravitational creep are $\sim 1000 \mathrm{~m}$ high and the typical thickness and volume of the creeping rock-mass are $100 \mathrm{~m}$ and $10^{8} \mathrm{~m}^{3}$, respectively. Structural characteristics of saggings are cracks and uphill facing scarps together with trenches in the upper part and bulging in the lower part (Ampferer, 1939; Stini, 1941; Savage and Varnes, 1987; Bisci et al., 1996). Crystalline rocks of a wide range of metamorphic grades may undergo deep-seated gravitational creep; most of these creeping rockmasses have not been significantly altered by weathering and can be described by the rheology of brittle rocks. Deformation has not been restricted to a sliding or a narrow sliding zone but has affected the whole moving rock-mass. Generally, the development of deep-seated gravitational creep has been strongly influenced by the rock structure.

The prime causes of sagging in the Alpine area seem to have been glacial retreat at $\sim 15000$ a B.P. (Zischinsky, 1969). During the last ice age (Würm), the ice surface had an elevation of about $2400 \mathrm{~m}$ in the area of the saggings we consider (Husen, 1987). The idea proposed is that glacial erosion over-steepened the valley flanks and after the retreat of the glaciers and the loss of a supporting ice column of about $1000 \mathrm{~m}$ height, the creep process started on some valley flanks. In the lower part of the slope of the later giant rockslide at Köfels, the increase of Coulomb stress was about $8 \mathrm{MPa}$, at Lesachriegel about $2 \mathrm{MPa}$ (Brückl, 2001). Substantial erosion of the river banks at the toe of the slope may also enhance movement. Another important parameter for slope stability is interstitial water. Rocks may be physically or chemically altered by water. The mechanical effect of interstitial water is the reduction of effective stress and frictional forces by the pore pressure and a push in the direction of the hydraulic gradient in case the water table is inclined (Jaeger, 1972; pp. 184-187). The tectonic stress field may also have an influence (Gerber and Scheidegger, 1969; Scheidegger, 1970). 


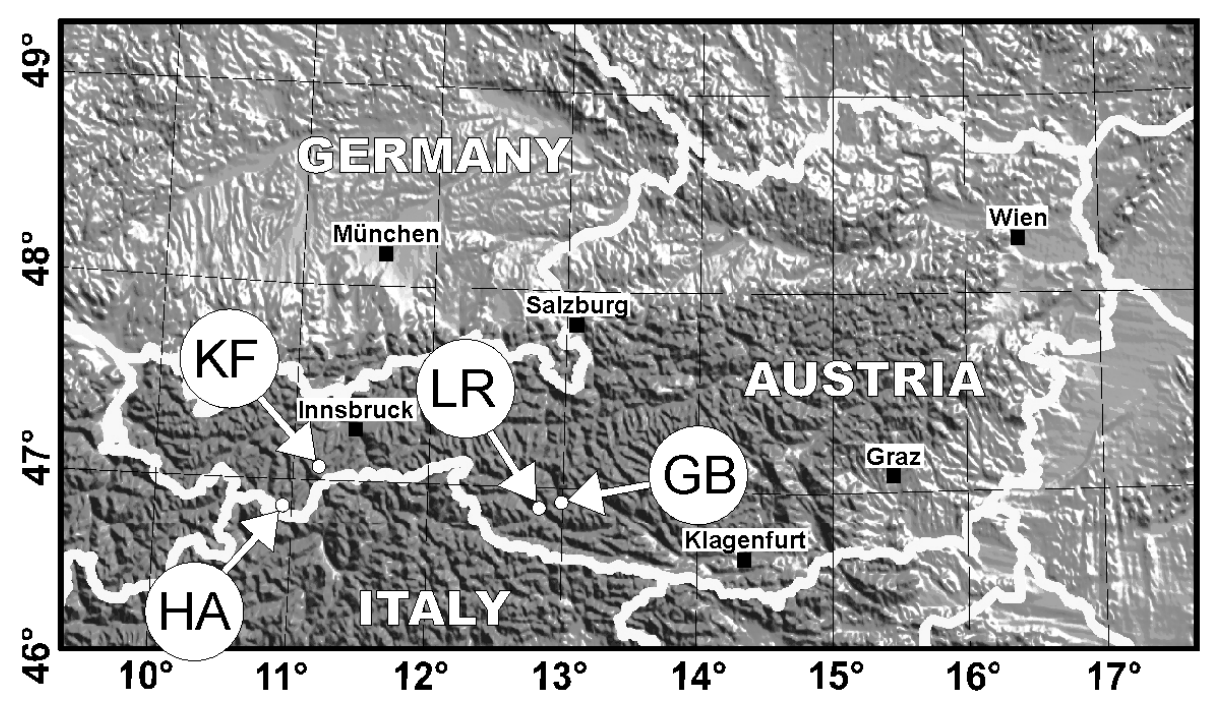

Fig. 1. Location of the mass movements Köfels (KF), Lesachriegel (LR), Gradenbach (GB) and Hochmais-Atemskopf (HA).

Table 1. Examples of deep-seated gravitational creep.

\begin{tabular}{|c|c|c|c|}
\hline Symbol & Location & Petrology & References \\
\hline KF & Köfels & Granite-gneiss (Augengneiss) & $\begin{array}{l}\text { Erismann et al. (1977) } \\
\text { Heuberger (1994) }\end{array}$ \\
\hline LR & Lesachriegel & Gneiss, mica shists and amphibolites & Hauswirth et al. (1979) \\
\hline GB & Gradenbach & Phyllites, calcareous mica shists of the Matreier rock formation & $\begin{array}{l}\text { Moser and Kiefer (1988) } \\
\text { Gottschling (1999) }\end{array}$ \\
\hline HA & Hochmais-Atemskopf & Paragneisses, micaschists, orthogneisses and amphibolites & $\begin{array}{l}\text { Tentschert (1998) } \\
\text { Brückl et al. (2004b) }\end{array}$ \\
\hline
\end{tabular}

Table 2. Area $(A)$, volume $(V)$, escarpment area $(A 0)$ and average discontinuous displacement $(s)$ on the basal plane of the mass movements KF, LR, GB and HA.

\begin{tabular}{ccccc}
\hline & $A\left[\mathrm{~km}^{2}\right]$ & $V\left[\mathrm{~km}^{3}\right]$ & $A 0\left[\mathrm{~km}^{2}\right]$ & $s[\mathrm{~m}]$ \\
\hline KF & 12.9 & 3.88 & 11.0 & 1622 \\
LR & 1.10 & 0.063 & 1.74 & 247 \\
GB & 1.68 & 0.121 & 1.68 & 40 \\
HA & 2.82 & 0.264 & 2.83 & 10 \\
\hline
\end{tabular}

Many sackung persist in creeping and stabilize after the centre of gravity has sagged down 100-200 m (vertical component of displacement). Representative examples for this behaviour are the Glunzerberg and Nassereiner Alm, Tyrol, Austria (Zyschinsky, 1969; Brückl and Scheidegger, 1972). However, there are also examples of mass movements which started through deep-seated creep but changed to rapid sliding. The main aim of this paper is to elaborate a model for a better understanding of both processes and the prediction of the transition to rapid sliding.

\section{Examples of deep-seated gravitational creep in rock}

This paper concentrates on four mass-movements which have been investigated for aspects of deep-seated gravitational creep and the prediction of the transition to rapid sliding. The locations of these mass-movements, all of which lie in crystalline complexes of the Austrian Alps are shown in Fig. 1. Brief petrological characterizations and references to geological and geomorphological descriptions have been compiled in Table 1. The possible influence of foliation and pre-existing joint sets on the generation of the mass movements will be discussed, together with the orientation and shape of the basal surface of the mass movements (Sect. 3).

Structural models of creeping rock-masses have been constructed at Köfels (KF) (Brückl et al., 2001), Lersachriegel (LR) and Gradenbach GB (Brückl and Brückl, submitted, $2004^{1}$ and HA (Brückl et al., 2004b). The thicknesses of the mass-movements have been derived from a combination of refraction seismic measurements (at KF also reflection seismic measurements) and all the available direct evidence

\footnotetext{
${ }^{1}$ Brückl, E. and Brückl, J.: Geophysical models of the Lesachriegel and Gradenbach deep-seated mass-movements (Schober range, Austria), submitted to Eng. Geology, 2004.
} 

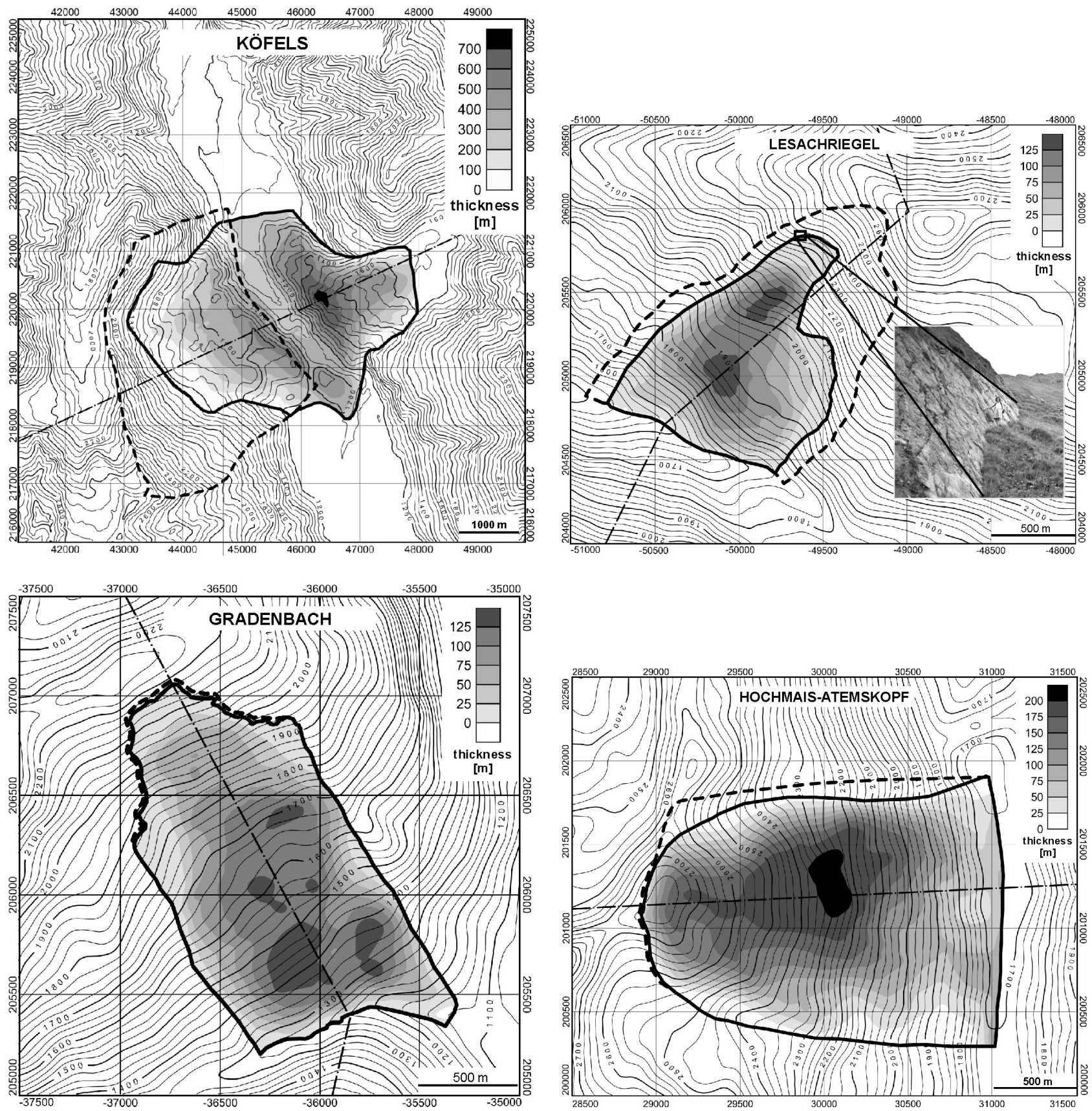

Fig. 2. Topography (contours from digital elevation model), boundaries (solid lines) and escarpment area (dashed lines) of the mass movements (a) KF, (b) LR, (c) GB, (d) HA. The thicknesses are superimposed in grey scale. The locations of the cross sections later shown in Fig. 5 are also marked (dash-dotted). A picture of the scarp generated in 1965 on LR is inserted into Fig. 2b.

from boreholes and galleries. Representative examples of refraction and reflection profiles from KF, LR, GB and HA may be found in the references given above. Figures $2 a-d$ show the digital terrain models, the boundaries of the moving rock-masses, the escarpment areas and the thicknesses of the mass-movements. In Table 2, values of the present day area and volume of the mass-movements have been compiled. Furthermore, the distance of discontinuous sliding along the basal surfaces has been derived from the extent of the scarps at the uphill end of the mass-movements and from the estimated overthrusting at the fronts (toes).

A significant relationship has been found between the Pwave velocity $(\mathrm{Vp})$ of the creeping rock-mass and the depth below the surface (D), measured normal to the dip of the average slope (Brückl and Parotidis, 2000; Brückl et al., 2004b). In establishing this relationship, the P-wave velocities have been reduced to dry conditions, using Gassmann's relation (Gassmann, 1951), in places where water saturation 

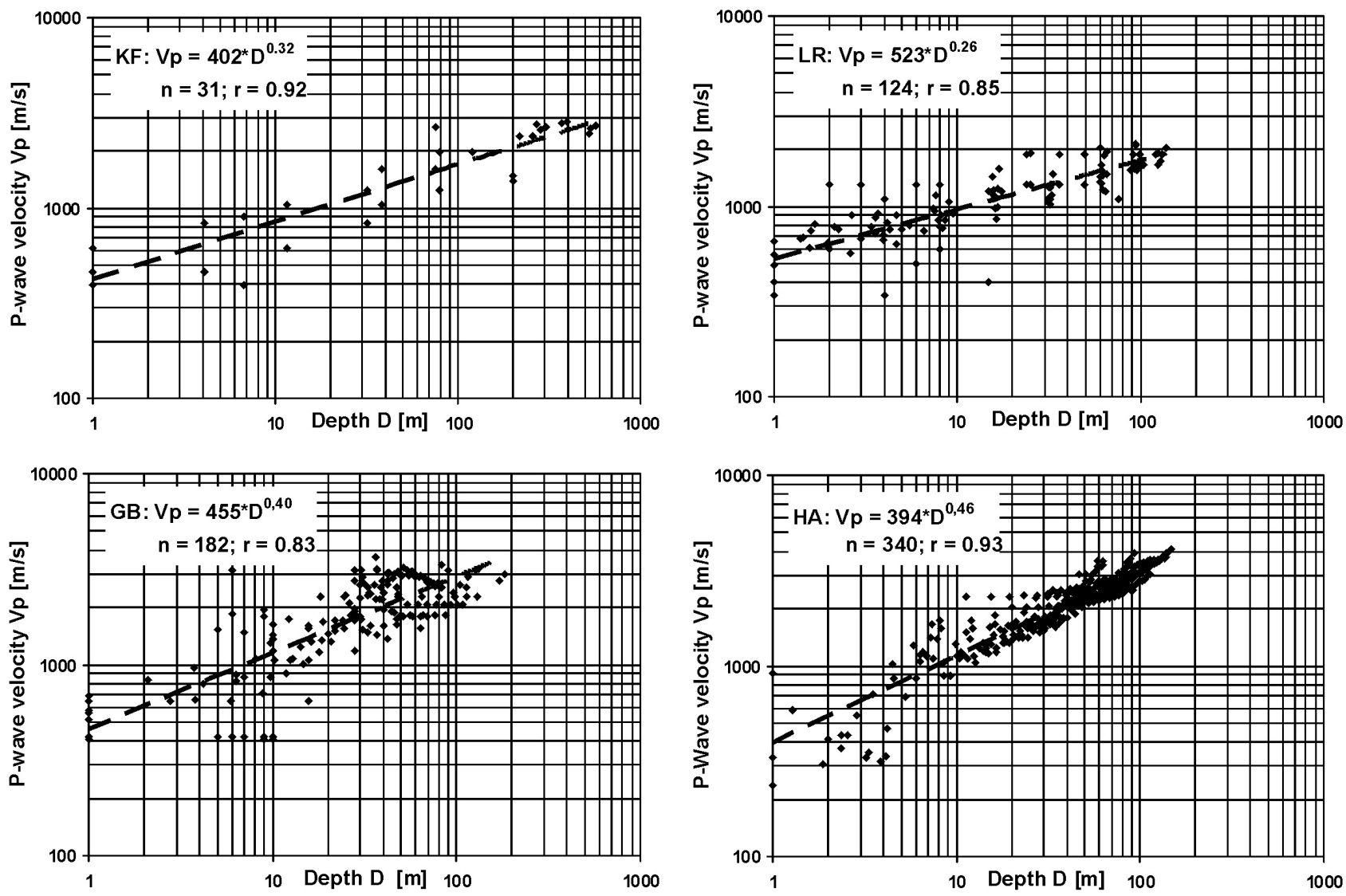

Fig. 3. Relations between longitudinal seismic velocity (reduced to dry conditions) versus depth of overburden of the mass movement with the resulting exponential trend lines, the number of data points and the correlation coefficients, (a) KF, (b) LR, (c) GB, (d) HA.

probably occurred. At KF, the water table has been correlated with a refractor about $10 \mathrm{~m}$ below the river bed and, at HA, with the water level of the hydroelectric power reservoir bordering the mass-movement at the toe of the slope. At GB, Moser and Kiefer (1988) report a shallow water table in the lower part of the slope in 1979. Vp data from a seismic campaign in that year has been reduced to dry conditions using this information. On LR, there is no information about the water table and no reductions have been performed. Figures $3 a-d$ show the log-log relationships between $\mathrm{Vp}$ and $\mathrm{D}$, together with the resulting trend lines, the number of data points and the correlation coefficients. The porosity of the moving rock-mass was estimated from the reduced seismic data using the relationship given by Watkins et al. (1972).

The present-day activity of the four mass-movements under consideration are quite different. In the 18th century, KF became famous when pumice was found at a sliding plane (Erismann et al., 1977; Erismann, 1979), resulting from friction along the sliding plane causing temperatures of over $1700^{\circ} \mathrm{C}$ to be generated; this was confirmed by laboratory experiments. According to the kinematic model of Erismann et al. (1977), no further sliding or has taken place since this event, which has been radiocarbon dated (calibrated to calendar years) to 9600 years B.P. It has been assumed here that a phase of deep-seated gravitational creep, during which the sliding plane developed, preceded the rapid rock-slide.
In 1965, during a period of high precipitation and severe floods, the whole sackung at LR slipped, producing a scarp with about $3 \mathrm{~m}$ horizontal displacement which can still be clearly seen today (see picture inserted in Fig. 2b). Geodetic measurements (Hauswirth et al., 1979) after this slip event have demonstrated that the mass-movement has decelerated to low creep velocities $(\sim 0.01 \mathrm{~m} / \mathrm{a})$. As a result, it is difficult to choose a mean creeping velocity of the present-day movement. The slip of $3 \mathrm{~m}$ in 1965 is here assumed to account for the total movement during 50 years.

For GB, much more observational data is available, since this slope has been under geodetic and geotechnical control for more than 30 years. Strong movements during the period of high precipitation which caused the slip at LR, resulted in catastrophic debris flows at GB. High displacement rates of $\sim 6 \mathrm{~m} /$ year were also observed during 19741975 (Kronfellner-Kraus, 1980). Weidner et al. (1998) reported horizontal displacements of $11.9 \mathrm{~m}$ in the upper part of the sagging mass and $7.4 \mathrm{~m}$ in the toe zone, for the period 1969 to 1991. From 1999 to 2003, an average creep rate of $0.3 \mathrm{~m} /$ year has been observed at 4 GPS stations distributed over the whole slope (Brunner et al., 2003). During the summer of 2001, a phase of accelerated movement, with a creep rate of $0.2 \mathrm{~m} / \mathrm{month}$, was observed. The most significant average values have been deduced from recent photogrammetric evaluations for the years 1962 and 1996 (Brückl et al., 

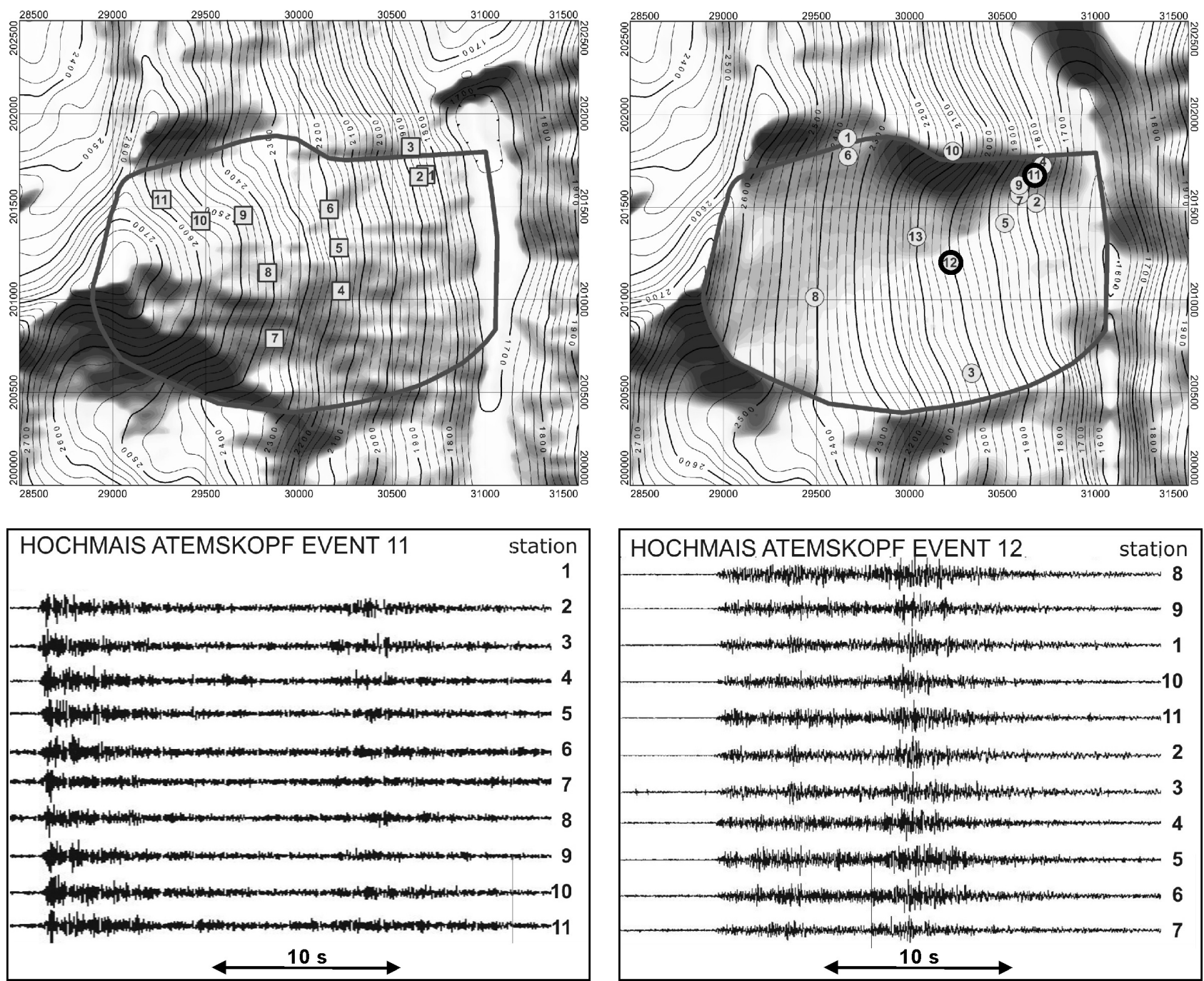

Fig. 4. Seismic monitoring at HA; (a) Location of 12 seismic monitoring stations (rectangles with station number); (b) 12 epicentres of seismic events detected during 3 days (circles with event number); (c) seismograms of event 11, traces with station numbers; (d) seismograms of event 12 , traces with station number.

2004a). For this period, the average horizontal displacement was $0.6 \mathrm{~m}$ /year. In the upper part of the slope, the displacements were slightly higher than in the lower part, although generally the displacements were remarkably uniform.

HA has been under geodetic and geotechnical control for the last four decades. The importance of these investigations is a consequence of the hydroelectric power reservoir (140 million $\left.\mathrm{m}^{3}\right)$ bordering the mass-movements (Tentschert, 1998). Several scarps define individual sliding slabs; the velocity of the most active slab is $30-40 \mathrm{~mm} /$ year at the surface and about $25 \mathrm{~mm} /$ year at its base. In the upper part of the slope, the creep rates drops to $<6 \mathrm{~mm} /$ year. A creep rate of $10 \mathrm{~mm} /$ year has been assumed to be representative for the present-day activity of the whole creeping rock-mass.

The creeping rock-masses of the four examples presented here have deformed in a brittle fashion. Therefore, it is expected that seismic events have accompanied the deformation processes. Seismic monitoring has been started on LR and GB; up to now, the total observation time for both massmovements has been about one month, with a maximum of 10 monitoring stations deployed simultaneously (Brückl et al., 2003). Examples of seismograms, together with the locations of the monitoring stations and the epicentres at HA are shown in Fig. 4. The 13 events for which the epicentres are shown in Fig. 4 have been observed within 3 days, the shortest time interval between the events was 8 min (between event 8 and 9), the longest $13 \mathrm{~h}$ (between event 4 and 5). Seismic moments have been estimated from the recordings using a relationship with maximum ground velocity and distance (McGarr and Bicknell, 1990). These seismic moments were converted to moment magnitudes $\left(M_{W}\right)$ by the relation of Hanks and Kanamori (1979). $M_{W}$ varies from -1.5 to 0.7 and has an average value $M_{W}=-0.4$. On GB, 16 seismic events of similar frequency content, duration and magnitude have been observed during a period of 12 days. 

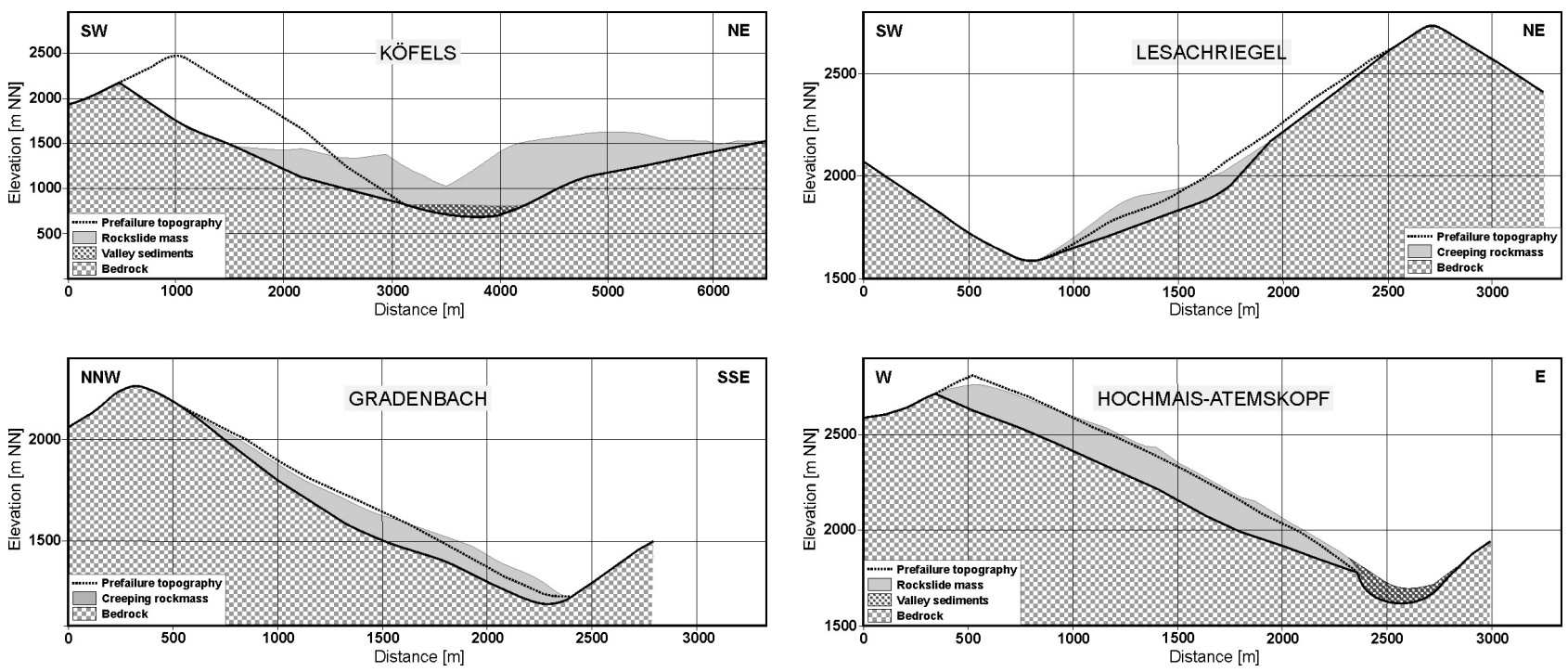

Fig. 5. Representative cross sections through the mass movements with actual surface, basal plane and reconstructed pre-failure surface for (a) KF, (b) LR, (c) GB, (d) HA. The location of these cross sections is marked in Fig. 2.

\section{Primary phase of deep-seated gravitational creep in rock}

A remarkable observation at all four examples of deep-seated gravitational creep in rock studied here is that there were no pre-existing geological discontinuities or planes of weakness which constituted the basal sliding surface. The foliation of the granite-gneiss (Augengneiss) at KF is of low mechanical significance and Erismann et al. (1977) did not consider the anisotropy during their experiments on friction and rock melting. At LR, the foliation dips steeply $\left(\sim 75^{\circ}\right)$ to S (Hauswirth et al., 1979), much steeper than the basal surface. At GB (Moser and Kiefer, 1988) and HA (Brückl et al., 2004b), the dip direction of the foliation is about normal to the dip of the sagging slopes. On LR, GB and HA, joint sets have been observed by the authors referenced before, which support the development of a creeping rock mass but do not directly serve as basal surface or sliding plane. Therefore, it has been assumed that the primary phase of deep-seated gravitational creep comprises the development of the creeping rock-mass by processes discussed later.

\subsection{Reconstruction of the pre-failure topography}

Before trying to model the primary phase, the pre-failure topography had to be reconstructed. This has been done for $\mathrm{KF}, \mathrm{LR}$ and GB in 3-D, taking into account the conservation of mass, the dilation accompanying the disintegration of the creeping rock-mass, the surrounding morphology and the gradient of the slope in the direction of the movement (Brückl, 2001; Brückl and Brückl, submitted, 2004 ${ }^{1}$ ). A similar reconstruction has been carried out for HA in 2-D along the presumed centre flow line (Brückl et al., 2004b). Figures $5 \mathrm{a}-\mathrm{d}$ show cross-sections through the mass-movements, indicating the present-day and pre-failure topographies and the base of the moving rock-masses. These cross-sections have been input into the model of the primary phase.

\subsection{Numerical modelling of progressive damage}

One approach to model mass-movements is to use all the available geomorphological and geological information to construct the model. Thus existing faults, cracks, and other structures have been defined as input, and, with a model, stress and strain have been calculated (e.g. Castillo, 1997; Savage et al., 2000; Kreuzer and Hinteregger, 2001; Eberhardt et al., 2004). In contrast to these approaches Savage and Varnes (1987) used a homogenous and isotropic elastic medium without any geological structure in order to calculate the state of stress. They were able to model significant morphological features of gravitational spreading of steepsided ridges by the introduction of plastic yielding according to the Mohr-Coulomb criterion.

In this study, numerical modelling was started also from a homogeneous and isotropic elastic rock material which we term compact in its initial state. The term "compact" should not be understood in a rock-mechanical sense (high strength, few joints); it has been chosen to make a clear difference to the creeping rock-mass, which in a mineralogical sense, is the same as the compact rock-mass, but has been entirely damaged by new fractures. Damage takes place in zones of the model where a stress yield criterion has been satisfied. The damage has been numerically modelled by a reduction of the shear modulus. Additionally a dilatation corresponding to an average dilation angle of $\sim 5^{\circ}$ has been simulated by increasing a virtual temperature of the damaged rock material. After applying damage to the zones where the yield criterion has been satisfied, the model is no longer homogenous and 
Model A
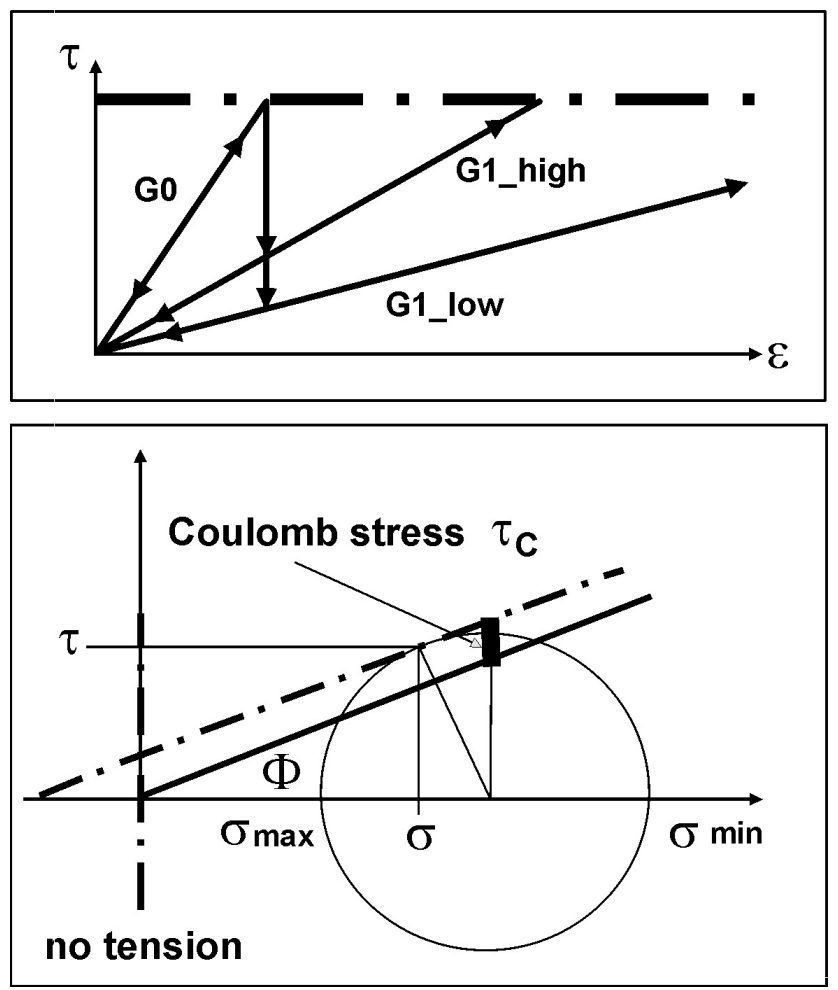

Model B
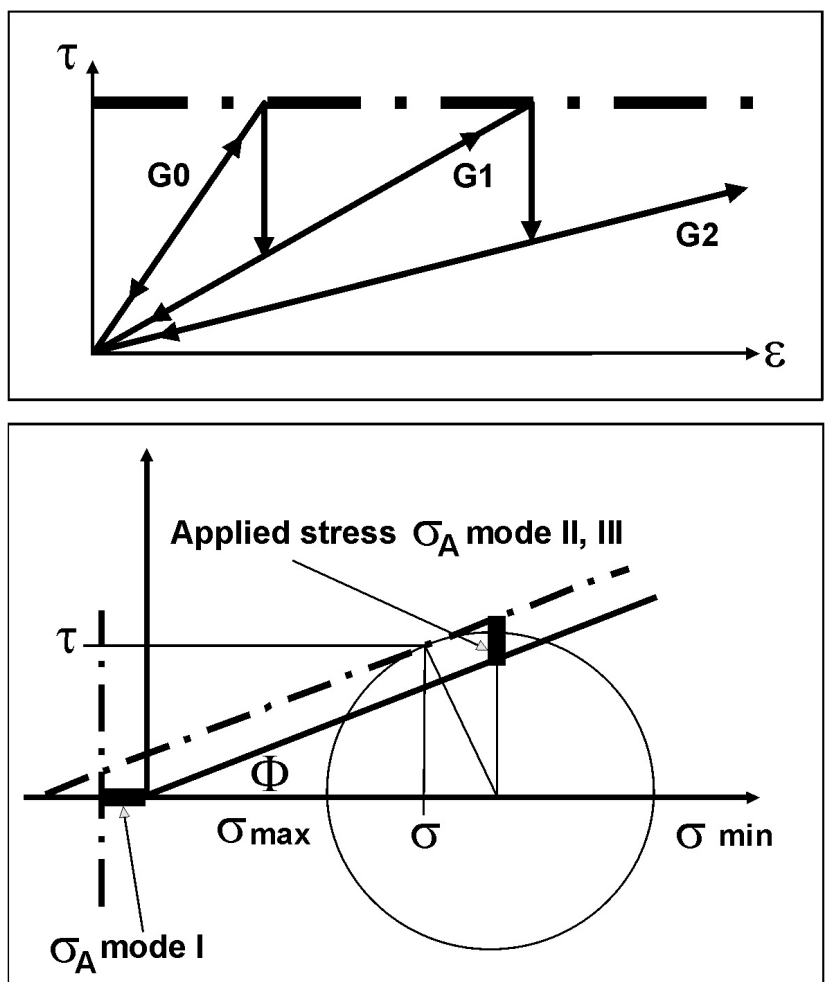

Fig. 6. Stress-strain diagrams for stress induced damage (above) and yield stress criteria in Mohr's circles (below). (a) Model A - single damage: The steepest stress-strain path corresponds to the shear modulus G0 of the compact rock, the middle stress-strain path to the shear modulus G1 high of the least damaged rock and the most gentle to the shear modulus G1_low of the most damaged rock. (b) Model B multiple damage: Again the steepest stress-strain path corresponds to the shear modulus G0 of the compact rock. The first damage reduces the shear modulus to G1, a second to G2 and so on (not shown in the diagram).

the state of stress must be recalculated. The lower shear modulus in the damaged zones causes a redistribution of stress and new zones satisfy the yield criterion and undergo further damage. The development of a creeping (damaged) rockmass on an originally homogenous and compact (in the sense defined before) rock slope can be modelled by the repeated recalculation of the state of stress and the application of damage. The difference to numerical modelling based on plastic yielding is that the changing elastic properties of the rock material, due to damage, control the progressive development of the creeping rock-mass and not the development of a zone of plastic yielding. The method presented here implies repeated numerical calculations of the elastic state of stress which always deliver a stable solution. On the other hand, only elastic deformation has been considered. Therefore, the method should only be used to model the initial phase of deep gravitational creep, during which the creeping rock-mass develops, and not larger displacements in a later phase.

In earlier investigations (model $\mathrm{A}$ ) concentrating on $\mathrm{KF}$, LR and GB (Brückl and Parotidis, 2001; Parotidis 2001), the yield criterion was defined by no-tension and Mohr-Coulomb failure criteria (Fig. 6a) where damage happened only once and the degree of damage was selected in order to quali- tatively model the dependence of the shear modulus with depth, inferred from the seismic results. The values of the damage factor $(k)$ applied to the shear modulus varied in the interval $1 / 4 \leq k \leq 1 / 160$ with the lowest values applied to the damaged rock material at the surface. The steepest stressstrain path in Fig. 6a corresponds to the shear modulus G0 of the compact rock, the middle stress-strain path to the shear modulus G1_high of the least damaged rock and the most gentle to the shear modulus G1_low of the most damaged rock. Deformation along these stress-strain paths is reversible but the transition from the compact to the damaged state is irreversible.

In subsequent numerical studies on GB and HA (model B), the maximum applied stress $\left(\sigma_{A}\right)$ for fracture modes I (opening), II (sliding) and III (tearing) was used as a stress yield criterion (Fig. 6b). For a definition of the fracture modes and the applied stress $\sigma_{A}$ see, for example, Lawn (1993, pp. 24, 31). Furthermore, and in contrast to model A, the modelling allowed for multiple damage when the applied stresses repeatedly reached the yield criteria in damaged zones. The damage factors $k=1 / 4,1 / 8,1 / 16$ and 1/32 were successively applied. As in Fig. 6a, the steepest stressstrain path in Fig. 6 b corresponds to the shear modulus G0 of 
Table 3. Compressional $(K)$ and shear modul $(G)$ and angle of internal friction $(\Phi)$ used for damage modelling of KF, LR, GB and HA; the average Coulomb stress $\left(\tau_{C}\right)$ and the average applied stress $\left(\sigma_{A}\right)$ follow from the application of damage model A or B.

\begin{tabular}{ccccc}
\hline & KF & LR & GB & HA \\
\hline$K[\mathrm{~Pa}]$ & $2.15 \times 10^{10}$ & $1.53 \times 10^{10}$ & $1.58 \times 10^{10}$ & $1.67 \times 10^{10}$ \\
$G[\mathrm{~Pa}]$ & $9.92 \times 10^{9}$ & $3.28 \times 10^{9}$ & $7.27 \times 10^{9}$ & $7.69 \times 10^{9}$ \\
$\Phi\left[^{\circ}\right]$ & 28 & 29 & 25 & 25 \\
$\tau_{C}[\mathrm{~Pa}]$ & $2.1 \times 10^{6}$ & $0.5 \times 10^{6}$ & $0.4 \times 10^{6}$ & - \\
$\sigma_{A}[\mathrm{~Pa}]$ & - & - & $0.4 \times 10^{6}$ & $0.5 \times 10^{6}$ \\
\hline
\end{tabular}

the compact rock. The first damage reduces the shear modulus to $\mathrm{G} 1(=\mathrm{G} 0 / 4)$, a second to $\mathrm{G} 2(=\mathrm{G} 0 / 8)$ and so on. Again, deformation along these stress-strain paths is reversible but the transition from a less to a more damaged state is irreversible. The stress-strain paths shown in Figs. $6 a$ and $b$ are similar to those obtained from analytical models of the relationship between damage (crack growth) and elastic modulus (see Fig. 8 in Segall, 1984).

Laboratory experiments (Rao et al., 1999) have indicated that fracture toughness is approximately two to three times larger for fracture mode II than for mode I. Therefore, the most realistic yield criterion for tensional stress should be found between the no-tension criterion (model A) and the assumption of equal applied stress for all fracture modes (model B).

The elastic state of stress has been calculated by elastic 2D-FEM (Finite Element Method) calculations for the crosssections of the pre-failure topography shown in Figs. 5ad. The models used for the FEM-calculation were of much larger spatial extent, in order to avoid boundary effects. The input parameters of the models were the modulus of elasticity $(E)$, the shear modulus $(G)$, the angle of internal friction $(\Phi)$, and the damage factor $(k)$. For model A, damage was applied to all elements with tensional stress and a definite number of elements with the highest value of the Coulomb stress. For model $\mathrm{B}$, damage was applied to a definite number of elements with the highest values of $\sigma_{A}$ (either mode I, mode II, or mode III). Thereafter, for both models, the elastic state of stress was calculated again and the procedure repeated. This repeated damaging of the elements with the highest loading generated a fractured zone of comparable size and shape to that of the real mass-movement. The parameters were adjusted by trial and error in order to fit the observed crosssection of the creeping rock-mass. An additional degree of freedom came from assumptions concerning the water table; as described earlier (reduction of P-wave velocities from water saturated to dry conditions) only few constraints are available for this important parameter for the present-day situation and we are confronted with further uncertainties using this information to describe the water table during the initial phase of the mass movements. As pointed out before the models used for the FEM-calculation were of much larger spatial extent, in order to avoid edge effects. However, the area where the damaging procedure was applied had to be restricted to the areas shown in Figs. 7a-j. Otherwise, damage would have happened on other, apparently stable slopes. This was probably a consequence of disregarding the structural rock properties of the different slopes.

The results from model A for KF, LR, and GB which best fitted the cross-sections of the creeping rock-mass have been shown in Figs. 7a-f. Preliminary results for model B (GB and HA) have been shown in Figs. $7 \mathrm{~g}-\mathrm{j}$. The input parameters for have been compiled in Table 3 . The density was kept constant with $d=2600 \mathrm{~kg} / \mathrm{m}^{3}$. For the application of model A to KF, LR and GB (Figs. 7a-f), parameters have been found which gave satisfactory fits to the observed base of the massmovement and the extent of the damaged zone as calculated previously. The numerical modelling was most sensitive to the angle of internal friction $\Phi$. The preliminary results of the application of model B to GB and HA show clearly the development of a damaged zone which could develop into a sliding surface. However, this zone is deeper than the observed basal surface and further modelling efforts are necessary in order to achieve a better fit. An increase of the angle of internal friction from $\Phi=25^{\circ}$ to $\Phi=26^{\circ}$ resulted in a reduction of the applied stresses $\sigma_{A}$ from an average value of $0.5 \mathrm{MPa}$ to values $<0.1 \mathrm{MPa}$. We took $\sigma_{A}<0.1 \mathrm{MPa}$ as an indication that the process of progressive damage would not develop. Both models A and B confirm the conclusion that $\Phi$ is well constrained.

As pointed out before, in both models $\mathrm{A}$ and $\mathrm{B}$, the value of the yield stress (Coulomb stress, $\tau_{C}$, or applied stress, $\sigma_{A}$ ) was not defined in advance; it was chosen in order to maintain the process of progressive damaging of a definite number of elements for each iteration. The last two rows in Table 3 show the average values of the highest Coulomb or applied stresses for all successive iterations. These values define the magnitude of the stress necessary to maintain an ongoing damage process.

3.3 Comparison of model parameters with results from rock mechanical testing

Essential for comparing the model data with the results from rock mechanical testing is the assumption that the creeping rock has been generated from an originally compact rock by a process of progressive stress induced damage. As pointed out in Sect. 3.2, the term "compact" was chosen to make 

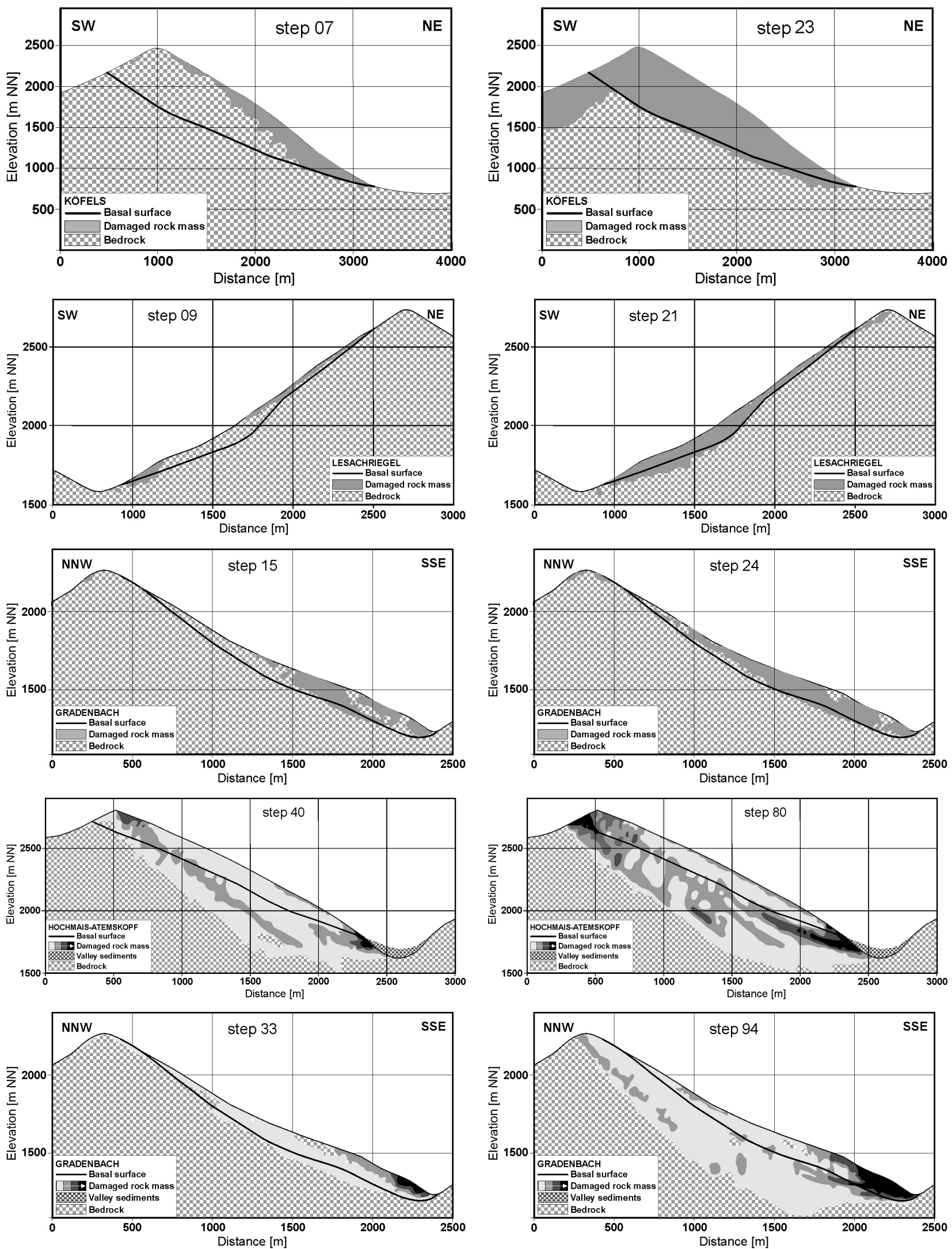

Fig. 7. Development of the zone of damaged rock after consecutive steps of progressive damage: (a) and (b): KF at steps 7 and 23 ; damage model A (c) and (d): LR at steps 9 and 21; damage model A (e) and (f): GB at steps 15 and 24; damage model A (g) and (h): GB at steps 33 and 94; damage model B (i) and (j): HA at steps 40 and 80; damage model B 
a difference to the creeping rock mass and not to exclude pre-existing joints and fractures. Alteration of the mechanical properties of the rock material by weathering or similar processes has been excluded. The results of the numerical models deliver values for the angle of internal friction between $25^{\circ}$ and $29^{\circ}$. Generally, published values for crystalline rock are higher than $35^{\circ}$ or even $40^{\circ}$ (Jaeger, 1972), although in environments of very high differential stresses or normal stresses, lower values of $\Phi$ can be expected. Hendron (1968) has given an example of a gneiss where, for differential pressures over $35 \mathrm{MPa}$, the corresponding value of $\Phi$ dropped from $43^{\circ}$ to $28^{\circ}$. A similar decrease in the angle of friction at high pressure can also be seen in Byerlee's law (Byerlee, 1978), which describes the strength of faults based on laboratory results, independent of rock type, and according to the normal stress $\sigma$ :

for $\sigma<200 \mathrm{MPa}$ (appr. $6 \mathrm{~km}$ depth) $\tau=\sigma_{e f f} \times 0.85[\mathrm{MPa}]$

for $\sigma>200 \mathrm{MPa} \tau=50+\sigma_{e f f} \times 0.60[\mathrm{MPa}]$

These equations estimate the angle of friction with $\Phi \sim 40^{\circ}$ and for higher values of $\sigma$, with $\Phi \sim 31^{\circ}$. Both Byerlee's law and the tests reported by Hendron (1968) demonstrate that for high normal pressures, the angle of friction is within or at least near the range of the values which have been found for $\Phi$ by the modelling described in this paper.

Another parameter of the model is the value of Coulomb stress $\tau_{C}$ or applied stress $\sigma_{A}$ at which damage has been introduced. For the investigated cases, the average Coulomb stresses of the finite elements subjected to damage were in the range of 0.4-2.1 MPa (Table 3). This range is significantly lower than the corresponding values coming from the example given by Hendron (1968) or from Byerlee's law. They are also clearly less than the typical values for rock strength. For example, Attewell and Farmer (1976) gave a tensile strength of 7-25 MPa and a shear strength of 14$50 \mathrm{MPa}$ for granite. In summary, the applied stresses for inducing damage in our model are significantly lower than the corresponding empirical geomechanical values for compact crystalline rocks. It has been assumed that even favourable conditions for the stress induced damage could not close this gap. If Coulomb or applied stresses for damage in the models are significantly lower than measured values for damage, this could appear to invalidate the model. Therefore, we consider subcritical crack growth in the next section.

\section{Subcritical crack growth}

In the previous sections, it has been demonstrated that the Coulomb stress $\left(\tau_{C}\right)$ or the applied stress $\left(\sigma_{A}\right)$ derived from the model have much lower values than would be expected from geomechanical testing. For this reason, critical crack growth under stresses corresponding to the fracture toughness could not have been the process controlling the development of the creeping rock-masses. Other processes must, therefore, have been responsible for crack growth and damage at a lower stress level. As the time-scale for the generation of deep creep is in the order of 1000-10000 years these processes may be very slow. Note that the present day average creep velocity is not representative of the whole process, which was initiated - according our assumption - after the retreat of the ice age glaciers 15000 a B.P. In the following section, subcritical crack growth has been assessed as a possible mechanism, as suggested by Brückl and Parotidis (2001).

\subsection{Phenomenon of subcritical crack growth}

Subcritical crack growth enables material to degrade at stresses well below the material strength. This theory, which is based on fracture mechanics principles (Atkinson and Meredith, 1987), describes the velocity of crack growth by a stress intensity factor $\left(K_{n}\right)$ and the fracture toughness $\left(K_{c}\right)$. The stress intensity factor, $K_{n}$, where $n=\mathrm{I}$, II or III according to the failure mode, represents the magnitude of the stress field at the crack tip (Lawn, 1993, p. 24). Two constitutive laws for crack growth have been defined; the equilibrium law and the kinematic law. The equilibrium law specifies that cracks begin to grow when a critical value of the stress intensity factor has been reached, which is called the fracture toughness $\left(K_{c}\right)$. When $K_{n} \geq K_{c}$, the crack growth velocity may reach the $S$-wave velocity of the material. The kinematic law states that for certain subcritical stress values (values smaller than the material strength) a crack growth velocity develops which is a function of the applied stress. Subcritical crack growth is valid for $K_{n}$ values greater than a lower limit $\left(K_{0}\right)$, which is suggested to be as low as $\sim 0.2 K_{c}$ (Atkinson and Meredith, 1987). There is a power law relationship between crack growth velocity and $K_{n}$ for $K_{n}>K_{0}$. This relationship holds up to values of $K_{n} \sim 0.8 K_{c}$. In the interval $0.8 K_{c}<K_{n}<1.0 K_{c}$, no further increase in crack growth velocity takes place, until dynamic rupture starts at $K_{n}=K_{c}$. The characteristic features of subcritical crack growth are summarized in Fig. 8.

The crack growth velocity can be significantly affected by the presence of agents such as fluids. An important example of subcritical crack growth is crack growth due to the chemical interactions between the crack tip and the environment. The phenomenon of chemical degradation because of environmental agents has been termed stress corrosion. In the range where the power law relationship between crack growth velocity and $K_{n}$ holds, the crack growth velocity is controlled by the rate of corrosion reactions at the crack-tip. In the interval $0.8 K_{c}<K_{n}<1.0 K_{c}$, the crack growth velocity is controlled by the transport rate of reactive substances to the tip. Therefore, in this phase the crack growth velocity no longer depends on $K_{n}$ and the applied stress. At $K_{n} \geq K_{c}$ dynamic fracture takes over as the controlling mechanism of the process, which is relatively insensitive to the chemical environment.

\subsection{Subcritical crack growth and creep velocity}

As outlined above, subcritical crack growth is relatively well understood and has been confirmed by laboratory 
investigations. Thus, it is reasonable to accept this process as a candidate for the process which allows for progressive damage and deformation of a previously compacted rockmass at a low stress level. A physical model relating progressive damage to deformation rate and creep velocity has not been established here. We assume a proportionality between the overall creep rate and the velocity of crack growth. This simple assumption may be justified if continuing deformation does not take place only by sliding and rolling but is controlled by the generation and growth of cracks and fractures. For a particular mass-movement, the creep velocity $(\mathrm{Vel})$ is defined at the centre of gravity.

As summarized above, there is a power law relationship between crack growth velocity and $K_{n}$ in the interval $0.2 K_{c} \leq K_{n} \leq 0.8 K_{c}$. Laboratory experiments on granite, summarized by Meredith and Atkinson (1987), show that this exponent has a value of about 8 or higher. For further consideration, the value 8 has been taken here. We disregard the influence of the changing length of the cracks which have to grow in order to maintain deformation. In this case, $\sigma_{A}$ is proportional to $K_{n}$ and the following relationship for the creep velocity $(\mathrm{Vel})$ has been formulated:

$V e l \propto \sigma_{A}^{8}$

Disregarding a systematic change in the crack length may be justified to some extent if the remaining compact parts of the rock are considered to be the obstacles controlling the deformation rate. However, we will later introduce a smoothing of the sliding surface (or zone) which can also account for the systematic growth of cracks in this zone.

In the primary phase of deep-seated gravitational creep, the whole volume undergoing creep has been damaged. The second phase of deep-seated gravitational creep is characterized by the concentration of shear into narrow zones and finally surfaces, especially the basal surface. Deformation concentrates along this surface and asperities are destroyed or smoothed, also by subcritical crack growth. This smoothing of the sliding surface has been observed and corresponds to the mechanism responsible for the reduction of the angle of friction in Byerlee's law for high normal pressures. Examples of slickensides have been seen, for example, on the 1965 generated scarp at LR (see picture inserted in Fig. 2b). Other smooth and remarkably planar sliding surfaces have been observed for example near HA (Brückl et al., 2004b) and at KF (Erismann et al., 1977).

Continued smoothing of the sliding surface reduces the applied stress $\sigma_{A}$ over an increasing part of this surface. Consequently, stress concentrations will be generated at the remaining asperities, and the stress concentration factor $(S C)$ has been introduced to account for this phenomenon. The relationship for the creep velocity during the second phase is then:

$V e l \propto\left(S C \times \sigma_{A}\right)^{8}$

Again, this relationship is linked to the movement of the centre of gravity. For the primary phase, $S C=1$. Friction on

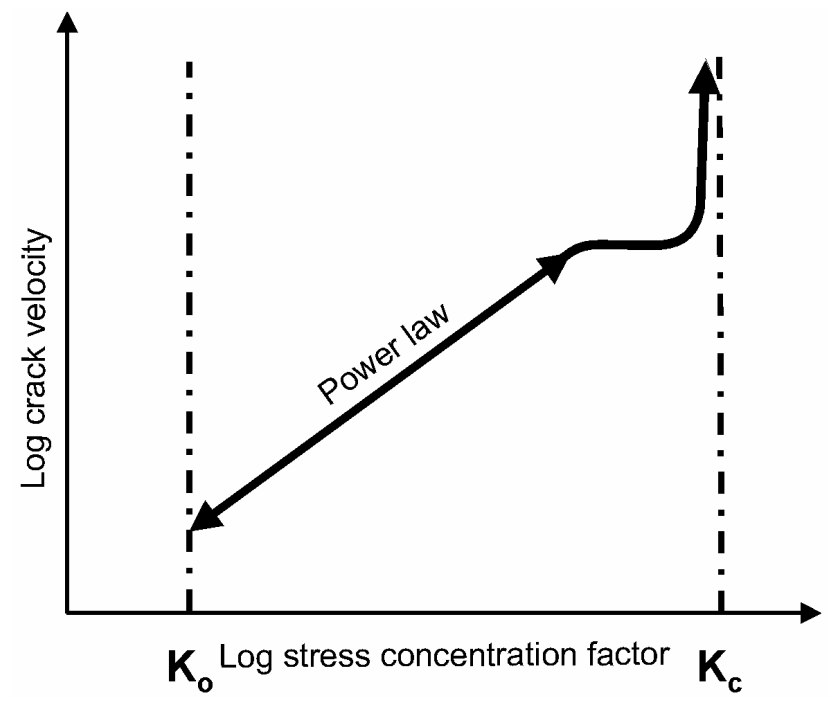

Fig. 8. Schematic diagram for fracture mode I crack growth because of stress corrosion (after Atkinson and Meredith 1987); $K_{c}$ is the fracture toughness for mode I, $K_{0}$ is a lower threshold of the process on subcritical crack growth.

the sliding surface may also be reduced by the generation of a breccia and fault gouge. This effect can also be modelled by Eq. (2); in this case, $S C$ should not be interpreted as a stress concentration factor, but as a factor considering the increase of the Coloumb stress because of the reduction of the angle of friction.

In the next step, the creep velocity is quantitatively related to the applied stress $\left(S C \times \sigma_{A}\right)$. As discussed above, subcritical crack growth occurs when the applied stress corresponds to stress intensity factors in the range of 0.2 to $1.0 K_{c}$. The power law relation holds between about $0.2 K_{c}$ and $0.8 K_{c}$. Assuming $\mathrm{Vel}=0.001 \mathrm{~m} / \mathrm{year}$ at $S C \times \sigma_{A}$ corresponding to $0.2 K_{c}$, the creep velocity at an applied stress corresponding to $0.8 K_{c}$ would be $V e l \sim 0.2 \mathrm{~m} / \mathrm{d}$. If this power law relationship held for the whole range of subcritical crack growth, then the creep velocity at the transition to dynamic rupture would be $V e l \sim 1 \mathrm{~m} / \mathrm{d}$. The highest observable creep rates in the regime of subcritical crack growth should be $\sim 0.2 \mathrm{~m} / \mathrm{d}$. Such high creep rates could describe accelerations which look like stick-slip at a low temporal resolution. Although the highest creep velocities (last phase of accelerating creep before rupture) reported for the Vajont rock-slide two years before the catastrophic rupture in 1963 were $0.08 \mathrm{~m} / \mathrm{d}$ (Erismann and Abele, 2001), it may be justifiably speculated that during the last hours before the catastrophe, the velocity was significantly higher.

\section{Secondary phase of deep-seated gravitational creep in rock}

By modelling the primary phase of deep-seated gravitational creep in rock, it has been found that Coulomb stress or applied stress is far too low to initiate dynamic rupture. 


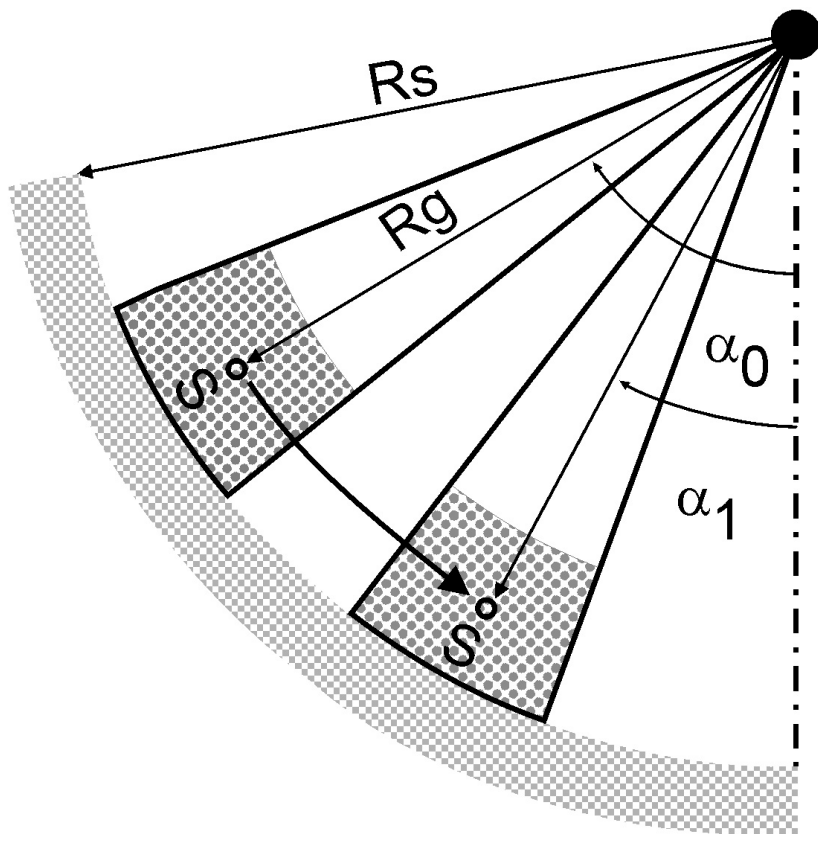

Fig. 9. Geometry of rotational slider block model. Rg: Radius pointing from the axis of rotation to the centre of gravity of the slider block; Rs: Radius of the sliding surface; $\alpha 0$ : Start angle between the plumb line and $\mathrm{Rg} ; \alpha 1$ : Angle between the plumb line and $R g$ at rupture (KF) or at present day (LR, GB, HA).

Subcritical crack growth has been introduced as a process which allows crack growth, and therefore creep, even under a low stress regime. As mentioned before, the secondary phase of deep-seated gravitational creep has been characterized by the concentration of shear into a narrow basal zone or a basal sliding surface. According to the model proposed here, asperities on the sliding surface are progressively smoothed, resulting in a stress concentration at the remaining asperities. Through this process, the applied stress at the asperities increases progressively up to the value at which the fracture toughness is reached at all asperities. At this moment, the transition to dynamic rupture of the whole slope takes place. Other processes leading to higher stress concentrations and crack growth velocities are a systematic increase of the crack length in the shear zone and/or the alignment of cracks in directions favouring crack propagation. For simplicity, all these processes have been summarized under the term "smoothing of the basal surface".

The concept and model of progressive smoothing presented here seems at a first sight to be a simplification of the Dieterich-Ruina law, which models the development of the coefficient of friction in terms of a state variable and the sliding velocity. The Dieterich-Ruina law has achieved great importance in earthquake modelling and prediction (Scholz, 2002). An asymptotic solution of this law results in a prediction of the time of failure by a linear extrapolation of the inverse of the velocity to zero (Voight, 1988, 1990). General solutions of the law have been applied successfully to the catastrophic Vajont rockslide and the La Clapiere mass-
Table 4. Parameters of the rotational slider block model; for the description of the parameters see Fig. 9 and the Appendix.

\begin{tabular}{ccccccc}
\hline & $R g[\mathrm{~m}]$ & $R s[\mathrm{~m}]$ & $\Phi\left[^{\circ}\right]$ & $\alpha 0\left[^{\circ}\right]$ & $\alpha 1\left[^{\circ}\right]$ & $V e l 1[\mathrm{~m} / \mathrm{a}]$ \\
\hline $\mathrm{KF}$ & 6497 & 6786 & 28 & 30.2 & 29.6 & 365 \\
$\mathrm{LR}$ & 4418 & 4462 & 29 & 30.9 & 27.7 & 0.06 \\
$\mathrm{~GB}$ & 5178 & 5242 & 25 & 27.6 & 27.2 & 0.6 \\
$\mathrm{HA}$ & 15550 & 15630 & 25.5 & 28.4 & 28.4 & 0.01 \\
\hline
\end{tabular}

movement (Helmstetter et al., 2004). However, the difference between these applications of the Dieterich-Ruina law and the approach presented in this article is that the development of the Coulomb stress at asperities (or apparent cohesion) is modelled here and the coefficient of friction (or angle of internal friction) is kept constant.

Continuing slip of the landslide body along the basal sliding surface may also result in lower gravitationally-induced stresses, because of the decreasing average slope angle. If this influence dominates, the creep process may effect a stabilisation of the slope. In the following section, the competition between these two processes by a geo-mechanical model have been described.

\subsection{Rotational slider block model}

A simple rotational slider block has been chosen to model the smoothing of the sliding surface and the change in gravitational stresses due to the rotation. The geometry of the model has been shown in Fig. 9. A description of all variables and parameters have been given in the Appendix. Applied stress can be replaced by Coulomb stress for a slider block model as both quantities are identical for shear mode failures. The Coulomb stress $\tau_{C}(\alpha, q)$ at the asperities on the sliding surface for arbitrary $\alpha$ (angle between the plumb line and the radius pointing from the axis of rotation to the centre of gravity of the slider block) and q (ratio between pore water and overburden pressure at the sliding plane), has been derived in the Appendix (Eq. A6). The stress concentration at asperities due to the smoothing of the sliding surface has been modelled by a stress concentration factor $(S C)$ increasing exponentially with displacement on sliding surface (Appendix: Eq. A5). The creep velocity is given by Eq. (2) and has been formulated as a function of $\alpha$ and $q$ in the following way (Appendix: Eq. A8):

$\operatorname{Vel}(\alpha, q)=\operatorname{Vel} 1 \times\left(\tau_{C}(\alpha, q) / \tau_{C}(\alpha 1, q)\right)^{8}$

The numerical values of the parameters necessary to calculate Coulomb stress and velocity have been compiled in Tables 2, 3 and 4. The quantities $\operatorname{Vel} 1$ and $\alpha 1$ are the values for velocity and $\alpha$ at rupture (KF) or at the present (LR, GB, HA). The values of $\alpha 1$, corresponding to a discontinuous displacement of $80 \mathrm{~m}$, and $V e l 1=1 \mathrm{~m} / \mathrm{d}$ are assumptions for KF. The value $s=1622 \mathrm{~m}$ given for KF in Table 2 is the present day discontinuous displacement after the rapid sliding phase 
and is not relevant for the considerations here. A density of $d=2200 \mathrm{~kg} / \mathrm{m}^{3}$ has been chosen for the creeping rock-mass.

According our assumption the initial phase of the massmovement started just after glacial retreat at 15000 a B.P. At KF, the instability occurred at 9800 a B.P. and the development of the mass-movement ended at that time. The other mass-movements have continued to develop. The present day creep velocity of these mass movements is higher than the average velocity calculated from the total displacement and the 15000 years since the glacial retreat. The primary phase of the mass-movement is the phase before a sliding surface has developed; during this phase, the stress concentration factor is therefore $S C=1$. Assuming an internal shear deformation of $100 \%$ at the end of the initial phase, the displacement of the centre of gravity is the thickness of the block. Estimates of the internal shear deformation using reconstructions of the pre-failure topography and the actual digital terrain model give values in the range of 130-160\% (Brückl and Parotidis, 2000). The factor q considers the pore water pressure at the sliding surface. As pointed out earlier, there is very little information to constrain $q$. Therefore, values of $q=0.00,0.05$, $0.10,0.15,0.20,0.25,0.30$ have been used in the calculation. For LR, the calculations started with $q=0.075$, and 0.10 in order to keep the rock-mass moving.

Using the relationship for the velocity (3) and the additional data described, the time needed for the primary phase $\left(T_{i n i t}\right)$ and for the sliding during the secondary phase $\left(T_{\text {slide }}\right)$ have been calculated. The total time $\left(T_{\text {total }}\right)$ is the sum of $T_{\text {init }}$ and $T_{\text {slide }}$, which is 15000 years for LR, GB and HA and 5200 years for KF. In order to fit $T_{\text {total }}$ to these values, the parameter controlling the smoothing of the sliding surface $(s 0)$ must be selected properly. As a result, the variation of the Coulomb stress at the sliding surface $\tau C(\alpha, q)$ with increasing discontinuous displacement has been obtained (Figs. 10a-d). The creep velocity during the initial phase (Vel0) and the duration of the initial phase $\left(T_{\text {init }}\right)$ have also been determined. These quantities and $s 0$ have been compiled in Table 5 for the value of $q$ which has been assumed to be the most probable. Furthermore, the ratio of the stress concentration factor during the primary phase $\left(K_{\text {init }}\right)$ to the fracture toughness $\left(K_{c}\right)$ has been calculated from $\mathrm{Vel} 0$ and the assumption that $1 \mathrm{~mm} /$ year creep velocity corresponds to a ratio $K_{\text {init }} / K_{C}=0.2$. Disregarding a systematic change of the crack length, as has been done previously, the interval of the Coulomb stress (or apparent stress) which corresponds to subcritical crack growth can be indicated in Figs. 10a-d. If the Coulomb stress drops below the lower boundary, the mass-movement stops; if the Coulomb stress reaches the upper boundary, dynamic rupture and the transition to rapid sliding takes place.

On the basis of the variation of $\tau_{C}(\alpha, q)$ with increasing discontinuous displacement at the sliding surface shown in Figs. 10a-d, the development of the individual massmovements investigated here have been discussed below. The conclusions drawn from the models have been discussed critically later.
Table 5. Duration of the primary phase $T_{\text {init }}$, velocity during the primary phase $\mathrm{Vel0}$, characteristic length controlling the smoothing of the sliding surface $s 0$, ratio of stress concentration factor during initial phase $K_{\text {init }}$ to fracture toughness $K_{c}$, and corresponding ratio of pore pressure to effective normal stress $q$ for KF, LR, GB and HA.

\begin{tabular}{cccccc}
\hline & $T_{\text {init }}[\mathrm{a}]$ & $V e l 0[\mathrm{~m} / \mathrm{a}]$ & $s 0[\mathrm{~m}]$ & $K_{\text {init }} / K_{c}$ & $q$ \\
\hline $\mathrm{KF}$ & 5067 & 0.059 & 60 & 0.33 & 0.20 \\
$\mathrm{LR}$ & 5478 & 0.008 & 253 & 0.26 & 0.15 \\
$\mathrm{~GB}$ & 13431 & 0.005 & 62 & 0.25 & 0.20 \\
$\mathrm{HA}$ & 13755 & 0.007 & 189 & 0.26 & 0.20 \\
\hline
\end{tabular}

KF: The input data have been chosen to get a transition to rapid sliding and, of course, this transition must happen in the model. However, it is remarkable that this transition would have taken place even at very low pore-pressures $(q=0.05)$. Furthermore, the Coulomb stress level corresponding to subcritical crack growth is exceptionally high compared to LR, $\mathrm{GB}$ and HA. The upper boundary is about $3 \mathrm{MPa}$ which is an average value for the stress drop accompanying earthquakes (Kanamori and Anderson, 1975).

LR: During its development, this mass-movement never approached the transition to rapid sliding. At present, it is inactive at low pore water pressures. At higher pore water pressures $(q=0.3)$ the creep velocity would rise up to $4 \mathrm{~m} /$ year. However, this value is insufficient to completely account for the generation of a new scarp, with $\sim 3 \mathrm{~m}$ displacement, formed during a short period of heavy precipitation in 1965 (see inserted picture in Fig. 2b). This shortcoming has been discussed below.

GB: The development of the creeping rock-mass during the primary phase took $>10000$ years; since this time GB has been in an accelerating phase. As at LR, the creep velocity would rise to $4-5 \mathrm{~m} /$ year at higher pore-pressures. The explanation of the highest creeping velocities of $\sim 6 \mathrm{~m} /$ year, observed from 1974-1975, has been given in the discussion below. The acceleration phase of GB will continue and at a total slip at the basal sliding surface of $\sim 100 \mathrm{~m}$, a transition to rapid sliding should take place. Only additional stabilization at the toe of the slope can stop this development.

HA: As at GB, the primary phase took a very long time and today the mass-movement is in an early state of the secondary phase. At present, high pore water pressures will not severely accelerate the rate of movement. The massmovement could become unstable after a slip of about $200 \mathrm{~m}$. However, such a large displacement would change the gravitational stresses in a way not properly described by the model presented here.

\subsection{Seismic activity}

As briefly described, considerable seismic activity has been observed on GB and HA. How seismic activity could be related to the concept of subcritical crack growth as the 

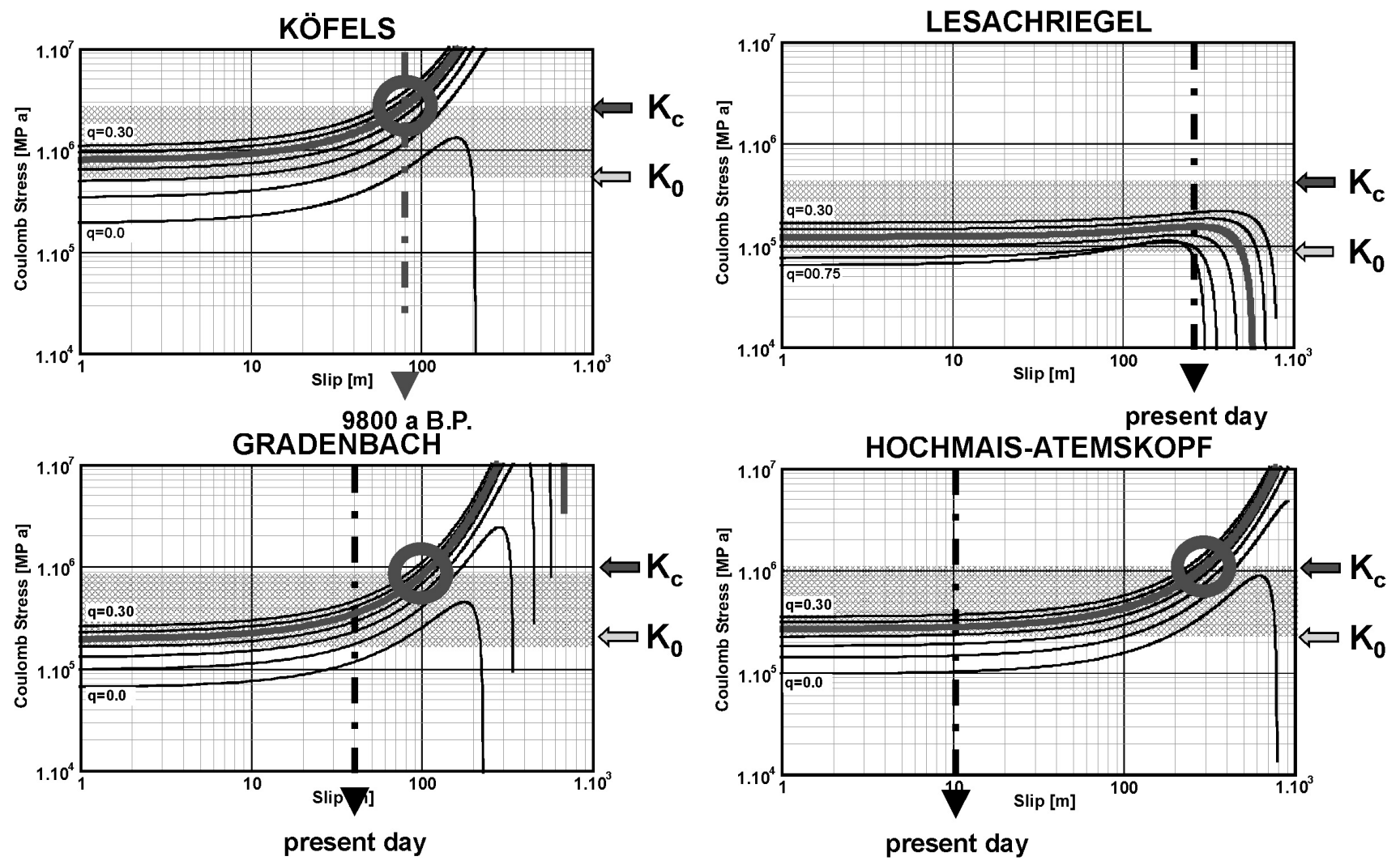

Fig. 10. Rotational slider block model, (a) KF, (b) LR, (c) GB and (d) HA: The diagrams show the Coulomb stress over slip ( $s$ ) at the sliding surface. The hatched stress intervals correspond to the subcritical crack growth regime between lower threshold $K_{0}$ and critical stress concentration $K_{c}$.

controlling process of slope movement has been discussed here. A prediction combining the seismic activity to the development of the sliding surface during the secondary phase of deep-seated creep has also been included.

Seismic activity has been assumed to be related to the generation of new fractures. In the model, new fractures are formed by subcritical crack growth, which would not generate any seismic energy. However, if a crack grows, the stress concentration factor at the crack tip will at some point reach a critical value and dynamic rupture, producing seismic energy, will take place. Therefore, seismic activity should be observed during the primary and the secondary phases. For the latter, the assumption has been made that seismic activity is proportional to the power consumed to overcome the asperities. In this case, seismic activity is proportional to the overall Coulomb stress, $\tau_{C} 0$, (related to the total sliding surface) and from Eq. (2) it follows:

$\tau_{C} 0 \propto 1 / S C \times V e l^{1 / 8}$

Therefore, the ratio of seismic energy to creep velocity will decrease with increasing smoothing (increasing $S C$ ). Information about the development of $S C$ and of a smooth sliding plane can be obtained by seismic monitoring plus observation of the creep velocity.

\subsection{Pore water pressure}

The relative sensitivity of the velocity versus pore water pressure, represented by the factor $q$, has been derived in the Appendix. According (A11) it is:

$d \ln \left(\operatorname{Vel}(\alpha, q)=\left[d \times g \times(V / F) \times \cos (\alpha) \times\left(\tan (\Phi) / \tau_{C} 0\right) \times d q\right]^{8}(5)\right.$

From Eq. (5), it can be seen that the relative sensitivity of the velocity to changing pore water pressures (represented by the factor $q$ ) increases as the overall Coulomb stress $\left(\tau_{C} 0\right)$, which is related to the total area of the sliding plane, decreases and the sliding surface becomes smoother. On the other hand, to achieve slope stabilization, the Coulomb stress must decrease. Therefore, reactivation of the massmovement by high pore water pressures at the sliding surface (higher than during the earlier development of the massmovement) is always a possibility, even when the process has been approaching a stable end. The formation of fault gouge or fine grained breccias may support the build-up of high pore water pressure.

\section{Discussion and Conclusions}

The conclusions drawn from the introduction of subcritical crack growth as the controlling process of deep-seated 
gravitational creep have been summarized as:

- Creep starts at applied or Coulomb stresses which are about $20 \%$ of the critical stress necessary to overcome fracture toughness.

- The velocity of subcritical crack growth is proportional to the 8th power of the applied or Coulomb stress; this relation holds for stresses between $20 \%$ and $80 \%$ of the stresses necessary to overcome fracture toughness. Between $80 \%$ and $100 \%$, there is no further increase of the velocity of crack growth.

- The velocity of the creeping rock-mass is proportional to the velocity of subcritical crack growth. The $20 \%$ stress level has been related to a creep velocity of $1 \mathrm{~mm} /$ year. From this assumption and the 8th power law, it follows that at the $80 \%$ level, the velocity is $0.2 \mathrm{~m} /$ day.

- An essential condition for instability of the creeping rock-mass is the concentration of deformation into a sliding surface. A progressive smoothing of the sliding surface is assumed. This process results in stress concentrations at asperities which finally reach the critical value to generate dynamic crack growth at all asperities. The transition to rapid sliding takes place at this point.

- In order to keep the creep process stable, the effect of progressive smoothing of the sliding surface must be compensated for by decreasing the gravitational stresses. This compensation is more effective the smaller the radius of curvature of the sliding surface.

- Sensitivity to changing Coulomb stresses and pore water pressure increases whilst seismic activity decreases, with progressive smoothing of the sliding surface.

The observable parameters describing the process of deepseated creep have been summarized as:

- Geometric parameters of the creeping rock-mass, especially those which are equivalent to the sliding angle and the curvature of the sliding surface of the rotational slider block model; geophysical exploration can deliver the necessary information.

- Cumulative slip along the basal sliding plane; from geomorphological mapping.

- Displacement rates; from terrestrial geodetic methods, GPS, InSAR, photogrammetry.

- Existence of a completely developed basal sliding surface; inclinometer measurements in several boreholes and/or a kinematic modelling of the whole massmovement based on observations of the mass balance and the surface velocity (Brückl et al., 2004a) can supply this information.

- Pore water pressure at the basal sliding surface, from piezometers and/or indirect geophysical methods.
- Seismic activity and its relationship to the total potential energy release (seismic efficiency); from seismic monitoring.

- The most important rock mechanical parameter is the angle of internal friction. This parameter can be derived from the modelling of the initial phase of creep.

These observable features are sufficient to define the rotational slider block model described above. Furthermore, observing the seismic efficiency and especially monitoring the sensitivity of the creep velocity to variations in the pore water pressure can supply additional information about the smoothing of the sliding surface. These data could be used to some extent for a validation of the hypothesis inherent in the rotational slider block model and give additional information on the degree of smoothing of the basal sliding surface. The following predictions could be made:

- Long term prediction from the modelling of the smoothing process in the past and an estimate of further smoothing and the expected change of gravitational stresses due to rotational sliding or other factors.

- Medium term prediction from the estimate of the actual state of development and the predictions about precipitation and expected changes of pore water pressure or other medium term changes of Coulomb stress (e.g. erosion).

- Short term warning from velocity monitoring; a velocity of $\sim 0.2 \mathrm{~m} /$ day corresponds to saturation of subcritical crack growth and dynamic rupture could take place at any time. Evacuation or other emergency measures would then be necessary, if the velocity approached this limit. As can be seen from Figs. 10a, c and d, a significant acceleration will be a precursor of such high velocities.

The approach to prediction of a dynamic failure of a slope exhibiting deep-seated creep presented here is based on several hypotheses not thoroughly validated so far; several simplifications have also been made. No difference has been made between the values of internal friction and friction on sliding surfaces and this angle has been kept constant for the whole process. Only the apparent cohesion has been modelled by a smoothing of asperities. The mathematical description given for the smoothing process is very simple whilst the physical understanding of the process is poor. The influence of pore water has been considered only by the effective stress, the effect of an inclined water table and the direct influence of water on material strength has been neglected. Nor are very high velocities during stick-slip motion covered by the model presented here. Furthermore, the creep velocities have been treated as quasi-continuous. In reality, the main part of displacement will only occur during phases of high pore water pressure. It is not yet clear how the angle of internal friction, which has been derived from the modelling of the damage process, is related to the results 
of creep experiments in the laboratory. In any case, the approach to prediction presented here should be used only in parallel with methods based on the state and velocity dependent friction laws. Besides further theoretical work, application of the model to more field examples is required. An important next step would be the gathering of data about the relationships between changing pore water pressure, velocity and seismic activity. With this data, the hypotheses that subcritical crack growth and progressive smoothing of the sliding surface are controlling factors of deep-seated creep could be checked.

\section{Appendix}

A rotational slider block (Fig. 9) has been chosen to describe the following items:

- Change in gravitational stresses due to the movement and smoothing of the sliding surface (Eqs. A6 and A7).

- Velocity of the centre of gravity as a function of displacement and pore water pressure (A8).

- Sensitivity of velocity to smoothing and pore water pressure (A11).

The variables and parameters necessary to describe the model are summarized below:

$\alpha \ldots$.. Angle between the plumb line and the radius pointing from the axis of rotation to the centre of gravity of the slider block $(R g)$.

$\alpha 0 \ldots \ldots \alpha$ at the begin of sliding.

$\alpha 1 \ldots \alpha$ at rupture (KF) or at present day (LR, GB, HA).

$\Phi \ldots$... Angle of friction at the sliding surface.

$\tau_{C} 0 \ldots$. Coulomb stress at the sliding surface.

$\tau_{C} \ldots$. Coulomb stress at the asperities of the sliding surface.

A.... Area of the sliding surface.

$d \ldots$. Density of the sliding rock-mass.

g.... Gravitational acceleration.

$q$... Ratio between pore water and overburden pressure at the sliding plane.

$p$.... Pore water pressure.

$R g \ldots$ Radius pointing from the axis of rotation to the centre of gravity of the slider block.

$R s . .$. Radius of the sliding surface.

$s$...Discontinuous displacement on sliding surface at rupture (KF) or at the present (LR, GB, HA).

$s 0 \ldots .$. Characteristic length controlling the smoothing of the sliding surface.

$S C$.... Stress concentration factor.

$V \ldots$... Volume of the sliding rock-mass.

$V e l . .$. Velocity of centre of gravity.

Vel1... Vel at rupture (KF) or at the present (LR, GB, HA).

The following moments determine the equilibrium of the rotational slider block:

Moment caused by gravitation:

$\mathrm{Mg}=\mathrm{d} \times \mathrm{g} \times \mathrm{V} \times \sin (\alpha) \times \mathrm{Rg}$
Moment caused by friction:

$M f=(d \times g \times V \times \cos (\alpha)-p) \times \tan (\Phi) \times R s$

Moment caused by Coulomb stress:

$M c=\tau_{C} 0 \times F / \cos (\alpha) \times R s$

Equilibrium of moments:

$M g+M f+M c=0$

The stress concentration at asperities due to the smoothing of the sliding plane has been modelled by a stress concentration factor $S C$ :

$\tau_{C}=S C \times \tau_{C} 0 \quad S C=\exp [(\alpha 0-\alpha) \times R s / s 0]$

The quantity $s 0$ has the dimension of a length and is the parameter controlling the smoothing of the sliding surface. The Coulomb stress at the asperities (A6) for an arbitrary $\alpha$ and $q$ follows from equations A1-A5. The quantity $q$ is the ratio between pore water and overburden pressure at the sliding plane (A7).

$\tau_{C}(\alpha, q)=\exp [(\alpha 0-\alpha) \times R s / s 0] \times d \times g \times(V / F) \times \cos (\alpha)$

$\times[(R g / R) \times \sin (\alpha)-(\cos (\alpha)-q) \times \tan (\Phi)]$

$q=p \times F \times(d \times g \times V \times \cos (\alpha))^{-1}$

The creep velocity is given by Eq. (2) and has been formulated as a function of $\alpha$ and $q$ in the following way:

$\operatorname{Vel}(\alpha, q)=\operatorname{Vel} 1 \times\left(\tau_{C}(\alpha, q) / \tau_{C}(\alpha 1, q)\right)^{8}$

The applied stress $\sigma_{A}$ has been replaced by the Coulomb stress $\tau_{C}$ in (A8) as both quantities are identical for shear mode failures. The relative sensitivity of the Coulomb stress versus pore-pressure, represented by the factor $q$, has been found by differentiating (A6). The relative sensitivity of the velocity (A11) follows from Eqs. (2), (A9), and (A10).

$$
\begin{aligned}
& d \ln \left(\tau_{C}(\alpha, q)\right)= \\
& \tan (\Phi) \times[\sin (\alpha) \times(R g / R s)-(\cos (\alpha)-q) \times \tan (\Phi)] \times d q \\
& d \ln \left(\tau_{C}(\alpha, q)\right)= \\
& d \times g \times(V / F) \times \cos (\alpha) \times\left(\tan (\Phi) / \tau_{C} 0\right) \times d q \\
& d \ln (V e l(\alpha, q)= \\
& {\left[d \ln \left(\tau_{C}(\alpha, q)\right)\right]^{8}=} \\
& {\left[d \times g \times(V / F) \times \cos (\alpha) \times\left(\tan (\Phi) / \tau_{C} 0\right) \times d q\right]^{8}}
\end{aligned}
$$

Acknowledgements. This paper is part of a research funded by the Austrian Academy of Sciences within the Austrian contribution to IDNDR (International Decade of Natural Disaster Reduction) and ISDR (International Strategy for Disaster Reduction). We express our thanks to L. H. Blikra and W. Z. Savage for their thorough review and the valuable comments and suggestions. We further say our thanks to H. Rice for critically reading and correcting the paper.

Edited by: G. B. Crosta

Reviewed by: L. Blikra and W. Savage 


\section{References}

Attewell, P. B. and Farmer, I. W.: Principles of engineering geology, Chapman and Hall, London, 1045, 1976.

Ampferer, O.: Über einige Formen der Bergzerreissungen, Sitz. Ber. Akad. Wiss. Wien, m.-n. K1. 148, 1-14, 1939.

Atkinson, B. and Meredith, P.: The theory of subcritical crack growth with applications to minerals and rocks, in: Fracture Mechanics of Rock, edited by: Atkinson, B., Academic Press geology series, Great Britain, 111-166, 1987.

Bisci, C., Dramis, F., and Sorriso-Valvo, M.: Rock flow (sackung), in: Landslide Recognition, edited by: Dikau, R., Brunsden, D., Schrott, L., and Ibsen, M. L., John Wiley \& Sons, England, 150160, 1996

Brückl, E.: Cause-effect models of large landslides, Nat. Haz., 23, 291-314, 2001.

Brückl, E. and Scheidegger, A. E.: The rheology of spatially continuous creep in rock, Rock Mech., 4, 237-250, 1972.

Brückl, E. and Parotidis, M.: Seismic velocities of large rockslide masses, Proceedings of the 62nd EAGE Conference \& Technical Exhibition, Glasgow, Scotland, 2000.

Brückl, E., Brückl, J., and Heuberger, H.: Present structure and prefailure topographys of the giant rockslide of Köfels, Zeitschrift $\mathrm{f}$. Gletscherkunde u. Glazialgeologie, 37/1, 49-79, 2001.

Brückl, E. and Parotidis, M.: Estimation of large scale mechanical properties of a giant landslide on the basis of seismic results, Int. J. Rock Mech. Min. Sci., 38, 877-883, 2001.

Brückl, E., Pregesbauer, M., and Ullrich, C.: Seismic and gravimetric monitoring of deep creep in rock slopes, Geophys. Res. Abstr., Vol. 5, 07420, European Geophysical Society, 2003.

Brückl, E., Brunner, F. K., and Kraus, K.: The kinematics of a deep-seated mass movement derived from geophysical, GPS and photogrammetric data, Poster Presentation at EGU, 1st General Assembly, Nice, France, 25-30 April 2004a.

Brückl, E., Zangerl, Ch., and Tentschert, E.: Geometry and deformation mechanisms of a deep-seated gravitational creep in crystalline rocks, in: Proceedings of the ISRM Regional Symposium EUROCK 2004 \& 53rd Geomechanics Colloquy, edited by: Schubert, W., 229-232, 2004b.

Brunner, F. K., Zobl, F., and Gassner, G.: On the Capability of GPS for Landslide Monitoring, Felsbau, 21, 51-54, 2003.

Byerlee, J. D.: Friction of rocks, Pure Appl. Geophys., 116, 615626,1978

Castillo, E.: Untersuchung von Massenbewegungen mit geophysikalischen Methoden und FE-Modellrechnungen, PhD Thesis, Vienna University of Technology, Austria, 2001, 1997.

Dikau, R., Brunsden, D., Schrott, L., and Ibsen, M. L.: Introduction, in: Landslide Recognition, edited by: Dikau, R., Brunsden, D., Schrott, L., Ibsen, M. L., John Wiley \& Sons, England, 1-12, 1996.

Eberhardt, E., Stead, D., and Coggan, J. S.: Numerical analysis and progressive failure in natural rock slopes - the 1991 Randa rockslide, Int. J. Rock Mech. Min. Sci., 41, 69-87, 2004.

Erismann, T. H.: Mechanisms of large landslides, Rock Mech., 12, 15-46, 1979.

Erismann, T. H. and Abele, G.: Dynamics of rockslides and rockfalls, Springer, Berlin, 316, 2001.

Erismann, T. H., Heuberger, H., and Preuss E.: Der Bimsstein von Köfels (Tirol), ein Bergsturz-“Friktionit”, Tschermaks Mineralogische und Petrographische Mitt., 24, 67-119, 1977.

Gassmann, F.: Über die Elastizität poröser Medien, Vierteljahresschr. d. Naturforsch. Ges. Zürich, 96, 1-22, 1951.
Gerber, E. K. and Scheidegger, A. E.: Stress-induced weathering of rock masses, Eclogae Geol. Helv., 62/2, 401-405, 1969.

Gottschling, H.: Der Talzuschub Gradenbach - ein geologischgeotechnischer Überblick, Jb. Geol. B.-A., Wien, 141/4, 345367, 1999.

Hanks, T. C. and Kanamori, H.: A moment magnitude scale, J. Geophys. Res., 84, 2348-2350, 1979.

Hauswirth, E., Pirkl, H., Roch, K., and Scheidegger, A. E.: Untersuchungen eines Talzuschubes bei Lesach (Kals, Osttirol), Verh. Geol. B.-A.,Wien, 2, 51-76, 1979.

Helmstetter, A., Sornette, D., Grasso, J.-R., Andersen, J. V., Gluzman, S., and Pisarenko, V.: Slider-block friction model for landslides: Application to Vaiont and La Clapiere landslides, J. Geophys. Res., 109, B02409, doi:10.1029/2002JB002160, 2004.

Hendron, A. J.: Rock mechanics in engineering practice, edited by: Stagg, K. G. and Zienkiewicz, O. C., John Wiley \& Sons, Great Britain, 21-51, 1968.

Heuberger, H.: The giant landslide of Köfels, Ötztal, Tyrol, Mountain Research and Development, 14/4, 290-293, 1994.

Husen van, D.: Die Ostalpen und ihr Vorland in der letzten Eiszeit (Würm), Map 1: 500000 , Geologische Bundesanstalt, Wien, 1987.

Hutchinson, J. N.: General Report: Morphological and geotechnical parameters of landslides in relation to geology and hydrology, in: Proc., 5th International Symposium on Landslide, edited by: Bonnard, C. and Balkelma, A., Rotterdam, Netherlands, 1, 3-35, 1988.

Jaeger, Ch.: Rock mechanics and engineering, Cambridge University Press, London, 417, 1972.

Kanamori, H. and Anderson, D. L.: Theoretical basis of some empirical relations in seismology, Bull. Seismological Soc. Am., 65/5, 1073-1095, 1975.

Kreuzer, E. and Hinteregger, E.: Schäden an einem Tunnel zufolge Hangkriechens - Schadensbild, Ursachen, Sanierung, Felsbau, 1, 14-24, 2001.

Kronfellner-Kraus, G.: Neue Untersuchungen in Wildbächen - Der Talzuschub in Abhängigkeit von Niederschlägen, Int. Symp. Interpraevent, Bad Ischl, 1, 179-192, 1980.

Lawn, B.: Fracture of brittle solids, second edition, Cambridge University press, 378,1993

McGarr, A. and Bicknell, J.: Estimation of near-fault ground motion of mining-induced tremors from locally recorded seismograms in South Africa. Rockbursts and seismicity in mines, editor Fairhurst, Balkema, Rotterdam, ISBN 906191145 1, 245 248, 1990.

Moser, M. and Kiefer J.: Die hydrogeologischen Verhältnisse und ihre Beziehungen zur Kinematik im Bereich der Talzuschubmasse Gradenbach/Kärnten, Steir. Beitr. z. Hydrogeologie, Graz, 39, 95-115, 1988.

Nemcok, A., Pasek, J., and Rybar J.: Classification of landslides and other mass movements, Rock Mech., 4, 71-78, 1972.

Parotidis, M.: Geomechanische Modellierung von Massenbewegungen, PhD Thesis, Vienna University of Technology, Austria, 2001.

Rao, Q., Stillborg, B., Sun, Z., Wang G., and Xu J.: Mode II fracture toughness testing of rock, 9th International Congress on Rock Mechanics, Paris, France, 731-734, 1999.

Savage, W. Z., Baum, R. L., Morrissey, M. M., and Arndt, B. P.: Finite-Element Analysis of the Woodway Landslide, Washington, U.S. Geological Survey Bulletin 2180, Only available online at http://geology.cr.usgs.gov/pub/bulletins/2180/, 2000. 
Savage, W. Z. and Varnes, D. J.: Mechanics of gravitational spreading of steep-sided ridges ("sackung"), International Assoc. of Engineering Geologists Bulletin, 35, 31-36, 1987.

Scheidegger, A. E.: Theoretical Geomorphology, second rev. edition, Springer Verlag, Berlin, 434, 1970.

Scholz, C. H.: The mechanics of earthquakes and faulting, Cambridge University Press, 439, 1990.

Segall, P.: Rate-dependent extensional deformation resulting from crack growth in rock, J. Geophys. Res., 89/6, 4185-4195, 1984.

Stini, J.: Unsere Täler wachsen zu, Geol. U. Bauw., Wien, 13/ 3 , 71-79, 1941.

Tentschert, E.: Das Langzeitverhalten der Sackungshänge im Speicher Gepatsch (Tirol, Österreich), Feldbau, 16/3, 194-200, 1998.
Voight, B.: A method for prediction of volcanic eruptions, Nature, 332, 125-130, 1988.

Voight, B.: Material science laws applies to time forecast of slope failure, In: Proc., 5th International Symposium on Landslide, editor C. Bonnard, A. Balkelma, Rotterdam, Netherlands, 3, 14711472, 1990.

Watkins, J. S., Walters, L. A., and Godson, R. H.: Dependence of in-situ compressional wave velocity on porosity in unsaturated rocks, Geophys., 37/1, 29-35, 1972.

Weidner, S., Moser, M., and Lang, E.: Influence of hydrology on sagging of mountain slopes ("Talzuschübe") - new results of time series analysis, 8th International IAEG Congress, Balkema, Rotterdam, ISBN 9054109904, 1259-1266, 1998.

Zischinsky, U.: Über Sackungen, Rock Mech., 1, 30-52, 1969. 